\title{
A mercantilização da água na Amazônia
}

\section{Sandoval Alves Rocha ${ }^{1}$}

A partir da década de 1970, o modo de produção capitalista adquiriu um novo impulso, apoiando-se nas inovações tecnológicas, na criação de novos produtos, na reconfiguração da divisão internacional do trabalho, assim como na mundialização dos mercados. Liszt Vieira (2013) percebe um crescimento do comércio e do investimento internacional mais rápido do que o da produção conjunta dos países, o que ampliou as bases internacionais do capitalismo e uniu o conjunto do mundo num círculo único de reprodução das condições humanas de existência. Para este autor, apoiando-se na expansão da tecnologia da informação, esta nova era elevou os processos econômicos, empresariais e os mercados financeiros ao primeiro plano e universalizou aspirações e utopias ocidentais, marginalizando estruturas sociais, processos e movimentos sociais particulares.

Este autor também afirma que os agentes mais dinâmicos da globalização são os conglomerados e empresas transnacionais que dominam a maior parte da produção, do comércio, da tecnologia e das finanças internacionais. Desta forma, o mercado, impulsionado por estes agentes, se tornou a matriz estruturadora da vida social e política da humanidade, sobrepondo-se às fronteiras nacionais. Neste contexto, as virtudes do mercado são mobilizadas como valores universais e o mercado financeiro comanda cada vez mais a economia global. As grandes corporações decidem sobre câmbio, taxa de juros, rendimento da poupança, dos investimentos e preço de commodities.

Trata-se de perceber que, como resposta à grave crise de acumulação de capital e ao avanço das tendências socialistas, as elites econômicas em articulação com os Estados de várias partes do mundo recorrem às práticas neoliberais como forma de retomar o crescimento e a estabilidade econômica do mundo capitalista. Ao falar sobre políticas neoliberais, estamos nos referindo às práticas políticas e econômicas como: a abertura comercial, a desregulação financeira,

${ }^{1}$ Padre Jesuíta, Doutorando em Ciências Sociais pela PUC-Rio. 
a privatização, a precarização do trabalho, a política de juros baixos e os incentivos à especulação. Na adoção destas práticas, não se deve perder de vista a intenção de estabelecer mecanismos que dizem respeito ao processo de geração dos lucros. De fato, o que expressa a recuperação da economia capitalista é o aumento da taxa de lucro, a qual por sua vez depende do crescimento da taxa de mais valia. Assim, obtendo sucesso na restauração do poder das elites econômicas, a doutrina neoliberal passa a configurar essencialmente a política e a economia da sociedade global, ampliando a extensão do mercado competitivo, mas elevando os níveis de desigualdades sociais (HARVEY, 2014).

Os principais guardiões dos ideais e das práticas neoliberais em todas as partes do mundo têm sido o Fundo Monetário Internacional (FMI), o Banco Mundial e a Organização Mundial de Comércio (OMC). Segundo Octávio Ianni (1996), estes são os guardiões dos ideais e das práticas do neoliberalismo, ou a santíssima trindade guardiã do capital em geral, um ente ubíquo, como um deus. Para este autor, sob todos os aspectos, seja proposta teórica ou ideológica, o neoliberalismo revela como se desenvolve a globalização pelo alto, ou de cima para baixo. Sempre privilegiando a propriedade privada, a grande corporação, o mercado livre de restrições politicas, sociais ou culturais, a tecnificação crescente e generalizada dos processos de trabalho e produção, a produtividade e a lucratividade.

Ao abordar o processo de globalização do capitalismo, Ermínia Maricato (2009) é enfática em ressaltar que nos países capitalistas centrais, o neoliberalismo gerou efeitos muito diferentes daqueles engendrados nos países periféricos. Os países centrais iniciaram a reestruturação produtiva a partir de uma base de pleno emprego ou de direitos universais relativamente extensos. Os países periféricos do capitalismo pouco avançaram na construção do Estado de Bem-Estar, iniciando a sua reestruturação produtiva numa base em que os direitos eram privilégios de alguns e onde a maioria da população nunca conheceu os direitos universais: emprego, previdência, saúde, educação e habitação. A desigualdade trazida pela globalização aprofunda e diversifica a desigualdade em sociedades historicamente desiguais. Para Maricato (2009), se para os países centrais a globalização significa a quebra do contrato social, para os países periféricos, ela implica uma nova relação de dominação e exploração. 
Harvey (2014) destaca o papel fundamental do Estado nas práticas neoliberais, pois compete a ele criar e preservar uma estrutura institucional apropriada a essas práticas. Além de criar mercados onde não existe (em áreas como a terra, a água, a instrução, o cuidado da saúde), o Estado deve também estabelecer as estruturas e funções militares, de defesa, da polícia e legais requeridas para garantir direitos de propriedades individuais e para assegurar o funcionamento apropriado dos mercados. No entanto, as intervenções do Estado devem se reduzir ao mínimo possível, deixando o campo livre para a atuação do mercado.

Neste cenário em que se verifica uma globalização crescente dos problemas ligados ao meio ambiente, a questão ambiental ganha relevância, recolocando a Amazônia como um dos elos estratégicos na disputa entre as nações pelo controle dos estoques de natureza. Segundo Berta Becker (2009), em épocas de tendências neoliberais, dilata-se a esfera da mercadoria, de forma que o processo de mercantilização da natureza gera mercados reais que buscam ser institucionalizados, configurando formas de governabilidade global sobre o ambiente planetário mediante o estabelecimento de regimes ambientais globais e sistemas de regras e normas para regular as ações nacionais, visando o controle das decisões sobre os seus territórios. Deste modo, o processo de mercantilização avança sobre a Amazônia, incorporando o seu patrimônio territorial e atribuindo valor econômico ao ar, à vida e à água (BECKER, 2009). Com a instituição generalizada da propriedade privada, possibilitando a apropriação da natureza, o processo de mercantilização transforma a Amazônia em fronteira do capital natural.

Becker vislumbra a valoração contemporânea do "mercado da água" como resposta à ameaça da escassez hídrica, decorrente do forte crescimento do consumo a tal ponto de ser considerado como o "ouro azul", capaz de, à semelhança do petróleo no século $X X$, instigar guerras no século $\mathrm{XXI}{ }^{2} \mathrm{~A}$ bacia amazônica contém a mais extensa rede hidrológica do planeta, com um total de 6.925.000 quilômetros quadrados desde seus nascentes nos Andes até sua foz no Atlântico.

\footnotetext{
${ }^{2}$ Escassez hídrica: A maior parte da água existente, entre $96,5 \%$ e $97 \%$, é salgada. A água doce representa uma parcela entre $2,5 \%$ e $3 \%$, dos quais $70 \%$ estão nas geleiras e calotas polares e outros quase $29 \%$ encontram-se nos aquíferos subterrâneos, restando pouco mais de $1,2 \%$ nas reservas superficiais, como rios, lagos e outros reservatórios (WHATELY; CAMPANILI, 2016).
} 
Abrange territórios de sete países sul-americanos, mas $63 \%$ estão localizados no Brasil. Esta abundância hídrica, de um lado, e a escassez em outras áreas do planeta, permitem visualizar o grande potencial da Amazônia para a exportação da água.

Mobilizada como mercadoria, a água ganha espaço nos diferentes círculos da sociedade moderna sendo concebida como commodity, recurso ou bem material capaz de exercer considerável influência e poder nas relações humanas. Segundo Francisco Barbosa e Francisco de Sá Barreto (2008), dentre os vários recursos naturais, de reconhecida importância social e econômica, a água deverá constituir-se num dos mais importantes recursos, detentor de enorme valor econômico agregado. Em escala global, 80 países já vivem em regime de escassez de água e, portanto, países detentores desse recurso terão a possibilidade de usá-lo com considerável poder de negociação. Essa valorização econômica da água tem gerado inúmeros conflitos, tanto entre países como entre regiões de um mesmo país, pela posse e controle das fontes.

A transformação da água em mercadoria implica grandes desafios para a universalização do abastecimento de água, uma vez que o acesso a este serviço ocorrerá mediante a inserção nas relações de domínio mercadológico, desconsiderando os setores economicamente mais vulneráveis, fragilizando o reconhecimento do direito humano à água e relativizando a obrigação do Estado e da sociedade em garantir o acesso de todos a este bem essencial. Neste interim, percebe-se o processo de reconfiguração da noção de cidadania. Se a pertença ao Estado significava a garantia dos direitos essenciais para a sobrevivência, agora, o acesso a eles ocorrerá mediante as relações de compra e venda. Sob esta perspectiva, Evelina Dagnino (2004) elucida que a questão social, que diz respeito ao problema da pobreza e das desigualdades não é mais vista a partir do prisma da construção da cidadania e da igualdade de direitos, mas é reduzida ao apelo à solidariedade para com os pobres, mobilizando a responsabilidade moral da sociedade, bloqueando a sua dimensão política e desmontando as referências à responsabilidade pública e ao bem público.

Ao tratar sobre a mercantilização da água, Riccardo Petrella (2002) identifica o predomínio de uma cultura tecnoeconomista. Para este autor, esta racionalidade leva a maioria dos seres humanos e a 
maior parte dos recursos da terra serem consideradas como produtos/objetos plenamente traduzíveis em valores econômicos (custos, preços, lucratividade, produtividade). Ana Domínguez, Marcel Achkar e Gabriela Fernández (2015) também percebem a predominância de uma visão fortemente orientada pelo paradigma dos negócios, através da qual se tem tentado converter a água em um bem econômico mercantil e, portanto, limitar seu acesso às pessoas que não estão em condições de enfrentar os custos dos serviços de água potável, da rede de esgoto e do tratamento de águas servidas.

O controle dos recursos hídricos na Amazônia, assim como a sua manipulação a serviço da acumulação capitalista podem ser evidenciados na privatização dos serviços de abastecimento de água e esgoto na cidade de Manaus, ocorrida no ano 2000. Além de transferir diretamente o controle da água para a iniciativa privada, a privatização promove a acumulação, consolidando o processo de espoliação urbana. Neste processo, o mercado não somente se apropria da força de trabalho, em troca de salários baixos e precárias condições de produção, mas também busca extorquir os trabalhadores, controlando as suas condições de reprodução, na medida em que se apropria dos serviços coletivos, como transporte, educação, saúde, moradia e saneamento básico. Estes serviços se materializam em equipamentos precários, dominantes, sobretudo, nas extensas periferias urbanas (KOWARICK, 2009).

A política do abastecimento de água e esgotamento sanitário em Manaus constitui um modelo de privatização onde se pode enxergar com clareza o processo de acumulação capitalista através da expropriação dos mais pobres. Isso pode ser visto no próprio processo de privatização da Manaus Saneamento, subsidiária da Companhia de Saneamento do Amazonas (COSAMA). Neste processo, as ações da subsidiária foram oferecidas na Bolsa de Valores do Rio de Janeiro por um preço mínimo de $\mathrm{R} \$ 183$ milhões de reais, sendo que o seu valor real equivalia a $R \$ 460$ milhões de reais. Ao final do conturbado processo de privatização, judicialmente suspenso por 4 vezes, o grupo francês Lyonnaise des Eaux arrematou a estatal por $\mathrm{R} \$ 193$ milhões de reais, adquirindo o direito de realizar os serviços de água e esgoto da cidade, através de uma concessão de 30 anos (posteriormente ampliada para 45 anos). 
A concessão dos serviços já passou pela gestão de vários grupos empresariais (Lyonnaise des Eaux, Solví, Água do Brasil e Aegea Saneamentos), mediante uma atuação insatisfatória, que beira à revolta popular. Além de se constatar a precariedade dos serviços, sobretudo, nas periferias da cidade, é comum a prática das cobranças indevidas, rendendo à empresa volumosos recursos de forma ilegal. Os últimos indicadores do Sistema Nacional de Saneamento Básico (SNIS/2016) indicam que a rede geral de abastecimento de água alcança $87,79 \%$ da cidade e a cobertura de esgoto não passa de $10,18 \%$ do território urbano. Este desempenho coloca Manaus na $5^{a}$ pior posição no ranking das 100 maiores cidade do Brasil, demonstrando a ineficiência da concessionária e 0 seu descompromisso para com o bem-estar da população. Este índice se torna mais dramático diante do fato de somente $64 \%$ da população estar ligada à rede geral disponível, sugerindo que um expressivo segmento populacional supre a necessidade de água através de outros meios, principalmente a perfuração de poços artesianos. Este índice também mostra o tipo de universalização almejada pela concessão privada. Busca-se a universalização de disponibilidade de rede, muito diferente da universalização do acesso à água potável, que é reconhecido como direito humano. Esta implica dedicar atenção específica para as populações que vivem em situação mais vulnerável, especialmente sob o ponto de vista econômico.

O SNIS também mostra que o valor da tarifa cobrada pelos serviços constitui o mais elevado da Região Norte e o $4^{\circ}$ mais caro do Brasil, indicando o intenso processo espoliativo em curso na capital amazonense. A ânsia pelo lucro ultrapassa qualquer princípio ético, chegando à negação da tarifa social para os setores mais empobrecidos da cidade. Dentre as 128 mil famílias detentoras do direito a este benefício (Dec. $n^{\circ} 2.748 / 2014$ ), somente cerca de 7 mil são atendidas pela empresa. ${ }^{3}$ Trata-se de uma política excludente, que lança na invisibilidade e na morte social aqueles que mais precisam do apoio da sociedade e do Estado. Além disso, chama a atenção a indiferença da empresa quanto às metas contratuais previstas para o serviço de esgotamento sanitário. Cerca de $90 \%$ da

3 REDAÇÃO. Manaus Ambiental prejudica mais de 900 moradores na zona norte. Portal Correio da Amazônia. Manaus, 13 dez. 2017. Disponível em: $<$ https://correiodaamazonia.com/manaus-ambiental-prejudica-mais-de-900moradores-na-zona-norte/> Acessada em: 13 de dezembro de 2017. 
cidade não possui este serviço, havendo numerosos casos em que os pagamentos são efetivados pelas famílias como se o serviço fosse realizado. Enquanto isso, os esgotos da cidade são lançados, quase totalmente, nos igarapés e rios, provocando graves prejuízos socioambientais.

A obsessão pela privatização, preconizada pela ideologia neoliberal, ganha maior visibilidade à medida que o Estado, mesmo diante dos descumprimentos contratuais, injeta vultosos recursos públicos no sistema de abastecimento de água, quando estes investimentos deveriam ser feitos pela concessionária. Somente até o ano de 2012, o Estado investiu $\mathrm{R} \$ 585$ milhões de reais nos serviços cuja responsabilidade é da empresa. ${ }^{4}$ Todos estes recursos significam benefícios para os empresários da água, que deixam de investir nos serviços, mas não renunciam à cobrança das tarifas aos consumidores. Trata-se de um Estado submetido aos interesses do mercado, atuando fortemente na garantia das margens de lucros empresariais, em detrimento da população que sofre pela precariedade dos serviços na cidade.

Para investigar a baixa qualidade dos serviços, a Câmara dos Vereadores do Município instaurou duas Comissões Parlamentares de Inquérito (CPI 2005 e CPI 2012). A partir dos resultados destas investigações, as CPIs recomendaram, nas duas ocasiões, a quebra do contrato de concessão e a responsabilização judicial da empresa e do poder público municipal, mas tais recomendações foram ignoradas pelos poderes instituídos e caíram no esquecimento, compondo mais um capítulo da sombria história da concessão. O Ministério Público do Estado também chegou a realizar investigações para identificar os responsáveis pela precariedade dos serviços. A este respeito, um dos procuradores afirma:

Atualmente, contam-se com cinco termos aditivos a esse contrato que nunca foram cumpridos, sendo que a concessionária vem se beneficiando, pelo vínculo ilegalmente celebrado, ao arrepio da lei, de favores do poder público, e mesmo assim não conseguiu mudar a realidade da cidade de Manaus. Faltam investimentos, compromissos, seriedade no trato da coisa pública, e isso está escancarado em nossos

${ }^{4}$ CARVALHO, Rosiene. Água: investimento de mais de $\mathrm{R} \$ 585$ milhões. Acritica. Manaus. 19 fev. 2012. Tema do Dia, p. A3. 
jornais diariamente. Diversas zonas da cidade ainda não têm sequer água potável. ${ }^{5}$

Em Manaus é possível perceber que os atores do mercado não colocam em primeiro lugar as necessidades da comunidade, mas a ampliação dos seus lucros. A mercantilização da água na Amazônia, não tem trazido resultados positivos para a população no seu conjunto, mas gerado exclusão para os setores mais pobres e elevados retornos financeiros para as empresas da água, consolidando o processo de acumulação. Eis as consequências de uma política pública que não visa ao bem comum, mas responder aos interesses empresariais.

É possível averiguar na gestão da água em Manaus, como os recursos naturais da Amazônia são apropriados pelo capital visando perpetuar o processo de acumulação capitalista em detrimento das necessidades da população e do equilíbrio ambiental. Trata-se de consolidar as condições de subcidadania, que são evidenciadas na violação de direitos básicos de um setor expressivo da sociedade. A história da integração autoritária da Amazônia continua sendo construída mediando a ação do Estado, que é capturado pelas forças do mercado e colocada a serviço dos interesses particulares. Resta incentivarmos a contrarreação dos movimentos da sociedade civil, que buscam defender a vida e apelam pela radicalização da democracia. Neste sentido, vale a pena estar atento às iniciativas das lideranças e coletivos locais, que inspirados no movimento de reconstrução da democracia brasileira, viabilizaram a promulgação da Constituição Cidadã (1988), fundamentada no principio do direito a ter direitos.

Diante desta realidade é necessário perguntar: 1) quais os interesses que movem a mercantilização da água? 2) Que classe social deve ser priorizada na elaboração das políticas públicas para que se possa promover o bem comum e realizar a justiça socioambiental?

${ }^{5}$ EDITOR, Processo que anula venda da Cosama está pronto para ser julgado na justiça. Portal D24am. 04 de maio de 2014. Disponível em: $<$ http://d24am.com/noticias/processo-que-anula-venda-da-cosama-esta-pronto-paraser-julgado-na-justica/>, Acesso em: 26 de janeiro de 2019. 


\section{Referências bibliográficas}

BARBOSA, Francisco; BARRETO, Francisco C. de Sá. Diferentes visões da água. In: BARBOSA, Francisco. (Org.). Ângulos da água: desafios da integração. Belo Horizonte: Editora UFMG, 2008.

BECKER, Berta K. Amazônia. Geopolítica na virada do III milénio. Rio de Janeiro: Garamond, 2009.

DAGNINO, Evelina. "Construção democrática, neoliberalismo e participação: os dilemas da confluência perversa". In: Política \& Sociedade. № 5, Outubro de 2004, pp. 139 - 164.

DOMÍNGUEZ, Ana; ACHKAR, Marcel; FERNÁNDEZ, Gabriela. As estratégias da sociedade frente aos processos de privatização da água: conquistas e desafios no Uruguai. In: CASTRO, José Esteban; HELLER, Léo; MORAIS, Maria da Piedade. (Editores). O Direito à Água como Política Pública na América Latina. Uma exploração teórica e empírica. Brasília: Ipea, 2015.

HARVEY, David. O neoliberalismo. História e implicações. 5ª Edição. São Paulo: Edições Loyola, 2014.

IANNI, Octávio. A Era do Globalismo. Rio de Janeiro: Civilização Brasileira, 1996.

KOWARICK, Lúcio. Escritos Urbanos. 2ª Edição, São Paulo: Editora 34, 2009.

MARICATO, Ermínia. Globalização e Política Urbana na Periferia do Capitalismo. Revista VeraCidade, Ano IV, no 4, Março de 2009.

PETRELLA, Riccardo O Manifesto da Água. Argumento para um contrato mundial. Petrópolis, RJ: Editora Vozes, 2002. 